\title{
Bounding Material Properties for Automotive Storage of Hydrogen in Metal Hydrides for Low-Temperature Fuel Cells
}

\author{
R. K. Ahluwalia ${ }^{1}$, J-K Peng and T. Q. Hua \\ Argonne National Laboratory, 9700 S Cass Avenue, Argonne, IL 60439, USA
}

\begin{abstract}
Metal hydride material properties required for on-board hydrogen storage for use with automotive polymer electrolyte fuel cell systems are discussed. Thermodynamic relationships between enthalpy and entropy of sorption are determined such that the storage system can be thermally integrated with the fuel cell system and be refuelled at reasonable $\mathrm{H}_{2}$ supply pressures of 50-200 atm. Simple criteria are developed for specifying minimum discharge kinetic rates needed to satisfy hydrogen demand on automotive duty cycles. Simple criteria are also developed for specifying minimum charge kinetic rates needed to refuel metal hydride tanks in reasonable time. Accessible intrinsic capacity and bulk density of the metal hydride are determined for the storage system to achieve system level targets for gravimetric and volumetric capacities. Based on these analyses, it is recommended that the storage media properties be measured on samples prepared by mixing the metal hydride with a high thermal conductivity material, and compacted to $600 \mathrm{~kg} \cdot \mathrm{m}^{-3}$ bulk density. The compact should have a minimum effective thermal conductivity of $8.5 \mathrm{~W} \cdot \mathrm{m}^{-1} \cdot \mathrm{K}^{-1}$.
\end{abstract}

Keywords: Metal hydrides; Hydrogen storage systems; Thermodynamics of sorption; Kinetics of sorption and desorption; Heat transfer

${ }^{1}$ Corresponding author: walia@anl.gov, 1-630-252-5979 


\section{Introduction}

Hydrogen storage in metal hydrides $(\mathrm{MH})$ continues to be regarded as a promising materialbased solution $[1,2]$ that with continued development may replace gaseous hydrogen storage in high-pressure tanks for automotive fuel cell systems (FCS). Many types of hydriding alloys and complexes have been investigated, including solid solutions, intermetallic compounds $\left(\mathrm{AB}_{5}, \mathrm{AB}_{2}, \mathrm{AB}, \mathrm{A}_{2} \mathrm{~B}\right.$, etc. $)$, transition and non-transition-metal complexes of borohydrides and alanates, and metastable hydrides [3]. Some of these hydrides are more suitable for non-automotive applications such as mobile devices, stationary power sources, and aerospace technologies. To date, intensive efforts on an international scale have not identified a metal hydride suitable for automotive applications [1, 2, 4].

A recent multi-year, multi-organization study evaluated four classes of developmental metal hydrides [4]: (1) destabilized hydrides (especially borohydrides and lithium hydride), including nano-confinement in nano-porous scaffolds; (2) complex anionic materials that contain well-defined chemical moieties with particular emphasis on alanates and borohydrides; (3) amide/imide materials, including mixtures of amides and borohydrides, amides and alanates, and $\mathrm{LiMgN}$; and (4) off-board regenerable materials $\mathrm{AlH}_{3}$ and $\mathrm{LiAlH}_{4}$ ). The study concluded that a metal hydride suitable for automotive hydrogen storage does not as yet exist and recommended that future work should focus on $\mathrm{LiBH}_{4} / \mathrm{MgH}_{2}$, $\mathrm{LiBH}_{4} / \mathrm{Mg}_{2} \mathrm{NiH}_{4}, \mathrm{Mg}\left(\mathrm{BH}_{4}\right)_{2}, 2 \mathrm{LiNH}_{2} / \mathrm{MgH}_{2}$, and $\mathrm{LiNH}_{2} / \mathrm{MgH}_{2}$. The purpose of this work is to establish specific targets for material properties to guide such future efforts.

The scope of this work is limited to on-board reversible metal hydrides, i.e., to the first three classes of materials listed above. Off-board regenerable materials, such as alane [5 - 7] and ammonia borane [8 - 10], have also attracted considerable attention recently, but transporting these materials, maintaining them in liquid form (liquid, slurry, or solution), loading and off-loading, and off-board regeneration cost and efficiencies remain as major 
obstacles [11 - 14]. The requirements for the off-board regenerable materials are different as they are largely dictated by these off-board issues rather than the on-board issues, such as heat transfer and sorption kinetics during refueling, for the reversible materials.

The scope of this work is further limited to low-temperature metal hydride (LTMH) systems, shown in Fig.1a, in which hydrogen desorbs at a temperature below the temperature at which the FCS coolant leaves the fuel cell stack. In an LTMH system, the waste heat generated in the stack can be used to liberate hydrogen from the metal hydride medium. It is distinguished from a medium-temperature metal hydride (MTMH) system, shown in Fig. 1b, in which hydrogen desorbs at a temperature higher than the temperature at which the coolant leaves the stack. In an MTMH system, some hydrogen must be burned to heat an intermediate fluid that is circulated through the MH bed to supply the enthalpy of desorption $(\Delta H)$. System simulations indicate $18-25 \%$ penalty in net system efficiency if an MTMH configuration is used with catalyzed sodium alanates [15]. There is also an additional penalty since some $\mathrm{H}_{2}$ must be burned to heat the MTMH bed to its operating temperature as the system starts up from cold.

In addition to a fill receptacle for $\mathrm{H}_{2}$, Fig. 1 includes flexible connections that must be made during refueling to an off-board cooling circuit that consists of a heat exchanger, valves, an off-board coolant and a coolant pump [15]. This circuit is needed since, depending on $\Delta H$ for absorption and $\mathrm{H}_{2}$ refueling rate, the heat load can be several hundred $\mathrm{kWs}$ (250 $\mathrm{kW}$ for $\Delta H$ of $20 \mathrm{~kJ} \cdot \mathrm{mol}^{-1}$ and $1.5 \mathrm{~kg} \cdot \mathrm{min}^{-1} \mathrm{H}_{2}$ refueling rate). The radiator on-board the vehicle can typically reject only a fraction of this heat load, and that too with the assist of ram air at cruising speeds $[16,17]$. Cross-contamination of the on-board and off-board coolants is also a concern and may be mitigated if the two fluids are chemically compatible or preferably have the same composition. 


\section{Material Requirements}

Table 1 lists some of the near-term and ultimate technical system targets for on-board hydrogen storage for light-duty fuel cell vehicles [18] that are relevant to the material covered in this work. Compared to stationary and material-handling applications, automotive duty cycles impose stringent requirements on $\mathrm{H}_{2}$ refueling rates and short transient response times for varying $\mathrm{H}_{2}$ flow rates from 10 to $90 \%$ and from 90 to $0 \%$ in order to accommodate fast dynamic changes in vehicular loads (sudden acceleration and braking). There are additional important targets for storage system cost, fuel cost, off-board efficiency (important for offboard regenerable materials), material stability (shelf life and durability over multiple chargedischarge cycles), fuel quality (i.e., purity of $\mathrm{H}_{2}$ from storage system) and environmental health and safety, but they are not specifically addressed here. The purpose of this section is to lay the rationale and foundation for translating these system-level targets to material-level requirements for on-board reversible metal hydrides.

Reference [18] should be consulted for a complete discussion of the basis and assumptions underlying the automotive storage system targets. Whereas Table 1 lists the target for usable $\mathrm{H}_{2}$ as $5 \mathrm{~kg}$ and Ref. [1] notes a large variability $(5.2-9.3 \mathrm{~kg})$ in the estimates of $\mathrm{H}_{2}$ requirement for different vehicle platforms and fuel economies, this study uses a value of $5.6 \mathrm{~kg}$ usable $\mathrm{H}_{2}$ to be consistent with earlier investigations [5, 15, 17]. Table 1 also lists $90 \%$ as the target for on-board efficiency, defined as the fraction of stored $\mathrm{H}_{2}$ that is available to the fuel cell. The on-board efficiency is taken as $100 \%$ in this study since its scope is limited to LTMH systems.

\subsection{Operating Temperatures}

Figure $2 \mathrm{a}$ shows a conceptual $80-\mathrm{kW}_{\mathrm{e}}$ automotive polymer electrolyte fuel cell (PEFC) system with compressed hydrogen storage that has been extensively analysed for performance and cost in several of our earlier studies $[16,17]$. In the present work, our 
objective is to determine the boundary conditions for a prospective metal-hydride hydrogen storage system that may potentially replace the 700-bar hydrogen storage tank in this FCS. Figure $2 b$ presents the FCS efficiency and the ethylene glycol coolant temperature at stack exit that vary between $47.5 \% / 85^{\circ} \mathrm{C}$ at rated power and $59.3 \% / 62^{\circ} \mathrm{C}$ under idling conditions. For a thermally integrated metal hydride system, in which the enthalpy of desorption $(\Delta H)$ comes from the waste heat produced in the stack and transferred to the stack coolant, the idling condition limits the maximum allowable $\Delta H$ to $100 \mathrm{~kJ} \cdot \mathrm{mol}^{-1}$ and sets the minimum desorption temperature to about $60^{\circ} \mathrm{C}$.

\subsection{Material Thermodynamics}

Maximum $\Delta H\left(\Delta H_{\max }\right)$ is further restricted by the requirement that, during discharge, the equilibrium pressure $\left(P_{e q}\right)$ at the minimum FCS coolant temperature $\left(60^{\circ} \mathrm{C}\right)$ should be higher than the target minimum delivery pressure (5 atm in Table 1 for 2017). Using the van't Hoff equation for plateau pressure [19],

$\ln \left(P_{e q}\right)=-\frac{\Delta H}{R T}+\frac{\Delta S}{R}$

one can determine the relationship between $\Delta H_{\max }$ and $\Delta S$ such that $P_{e q}$ equals 5 bar at $333 \mathrm{~K}$; this relationship is shown in Fig. 3a.

There is also a lower limit on $\Delta H$ since, during refueling, the equilibrium pressure at the maximum allowable bed temperature should be lower than the $\mathrm{H}_{2}$ supply pressure. Figure 3a includes the relationship between $\Delta H_{\min }$ and $\Delta S$ for $100^{\circ} \mathrm{C}$ maximum temperature and 50200 atm refueling pressures, as determined from Eq. (1).

An acceptable material should have $\Delta H$ between $\Delta H_{\min }$ and $\Delta H_{\max }$, as defined in Fig. 3a. Figure $3 \mathrm{~b}$ shows that some of the known materials in the MH database [20] have an enthalpy-entropy relationship that falls within this thermodynamic acceptability band [20], although they do not satisfy one or more other requirements as discussed below. 


\subsection{Containment Tank}

Type 3 tanks are generally preferred for containing metal hydrides if temperatures above $80^{\circ} \mathrm{C}$ are encountered during refueling [21]. These consist of an inner aluminium liner that is impervious to $\mathrm{H}_{2}$ and an outer layer of wound high strength carbon fiber-resin (CF) composite designed to withstand $225 \%$ of the nominal storage pressure. Table 2 summarizes the mechanical properties of the most-common in use high-strength and high-modulus T700S fiber and the fiber-resin composite with $60 \%$ T700S fiber by volume [22]. Prior to formal finite-element analysis using codes such as ABAQUS $[23,24]$, the tank geometry, optimal dome shape, winding angle, and preliminary helical- and hoop-layer thicknesses of the $\mathrm{CF}$ overwrap are generally determined by a netting analysis. A geodesic winding design for the dome, in which all fibers are uniformly stressed and display no shearing or bending stiffness, has a minimum mass of the $\mathrm{CF}$ composite for a given cylinder diameter and storage pressure [25 - 27]. Eqs. (2) and (3) can be used to determine the thicknesses of the helical and the hoop layers.

$t_{\alpha}=p R /\left(2 \sigma_{f, \alpha} \cos ^{2} \alpha\right)$

$t_{90}=p R\left(2-\tan ^{2} \alpha\right) /\left(2 \sigma_{f, 90}\right)$

where $p$ is the storage pressure, $R$ is the tank radius, $\alpha$ is the helical winding angle, $\sigma_{\mathrm{f}, \alpha}$ and $\sigma_{\mathrm{f}, 90}$ are design allowable stress of fiber in the helical layer and the hoop layer, respectively. Typically, the helical thickness is about half the hoop thickness in the cylinder section, and increases in the dome. Type 3 pressure vessels that are subjected to fluctuating pressure are auto-frettaged to generate residual compressive stresses in the liner, shift tensile loads to the CF composite, and extend the fatigue life of the metal liners [28]. SAE J2579 requires a fatigue life of 5500 pressure cycles at $125 \%$ of the nominal working pressure [29].

Figure 4 shows the weight and volume of 97-L Type-3 containment tanks as a function of storage pressure for designs in which the CF overwrap bears $85-90 \%$ of the pressure load 
with the balance being absorbed by the liner. The amount of CF needed is directly proportional to the storage pressure. For storage pressures under $100 \mathrm{~atm}$, the liner thickness is held constant at a minimum value, but it increases with increasing pressures above 100 atm. At the highest analysed storage pressure of $200 \mathrm{~atm}$, the containment tank accounts for $\sim 23 \%$ of the weight of an on-board storage system that stores $5.6 \mathrm{~kg}$ usable $\mathrm{H}_{2}$ and has $5.5 \%$ gravimetric capacity. For comparison, the containment tank for a 700-bar compressed hydrogen storage system accounts for $\sim 70 \%$ of the total system weight [21].

\subsection{Hydrogen Buffer Tank}

While starting from cold (ambient temperature $T_{a}$ ), a buffer tank may be needed to provide $\mathrm{H}_{2}$ for the duration of time that the bed takes to reach temperature $\left(T_{s}\right)$ at which the equilibrium pressure exceeds the minimum delivery pressure and the discharge kinetics is sufficiently fast to provide $\mathrm{H}_{2}$ at the target minimum full flow rate. The buffer capacity $\left(w_{\mathrm{H}_{2}}^{s}\right)$ is determined by the amount of $\mathrm{H}_{2}$ consumed in the PEFC stack while the stack and the $\mathrm{MH}$ bed heat to reach the start-up temperature. Recognizing that in a storage system without a burner, the bed (subscript b) is heated indirectly by using the waste heat produced in the stack (subscript FC), the required buffer capacity may be estimated from the following equation.

$$
w_{H_{2}}^{s}=\frac{\left(w_{F C} C_{F C}+w_{b} C_{b}\right)\left(T_{s}-T_{a}\right)}{\Delta H_{H_{2}}\left(1-\eta_{F C}\right)}-w_{H_{2}}^{p}
$$

where $w$ denotes the mass, $C$ is the heat capacity, $\Delta H_{H_{2}}$ is the lower heating value of hydrogen, $\eta_{F C}$ is the stack efficiency during start-up, and $w_{H_{2}}^{p}$ is the usable amount of gaseous $\mathrm{H}_{2}$ in the void space of the $\mathrm{MH}$ bed (i.e., amount of $\mathrm{H}_{2}$ available above $5 \mathrm{~atm}$ ).

Figure 5a presents an illustrative method of coupling the buffer $\mathrm{H}_{2}$ tank with the $\mathrm{MH}$ tank. The $\mathrm{MH}$ tank is charged with $\mathrm{H}_{2}$ at 100 atm and may reach a peak temperature of $116^{\circ} \mathrm{C}$ during refueling if the material has $\Delta H$ of $28 \mathrm{~kJ} \cdot \mathrm{mol}^{-1}$ and $\Delta S$ of $110 \mathrm{~J} \cdot \mathrm{mol}^{-1} \cdot \mathrm{K}^{-1}$. The buffer is discharged and supplies $\mathrm{H}_{2}$ to the PEFC stack during start-up while the bed temperature is 
below $20^{\circ} \mathrm{C}$ (actually $16.8^{\circ} \mathrm{C}$ for this material). Between refuelings, the buffer is replenished with $\mathrm{H}_{2}$ released from the $\mathrm{MH}$ bed during normal operation when the stack coolant is at near the peak temperature. The buffer pressure is limited to $40 \mathrm{~atm}$, which is the equilibrium pressure at $80^{\circ} \mathrm{C}$ for this material.

Figure $5 \mathrm{~b}$ presents the minimum total and usable (above 5 atm delivery pressure) amounts of buffer $\mathrm{H}_{2}$ needed for a single start from the indicated ambient temperatures. These results were obtained using Eq. (2) with the following values for the heat capacities of the stack $\left(w_{F C} C_{F C}\right)$ and the $\mathrm{MH}$ bed $\left(w_{b} C_{b}\right)$ and other parameters: $w_{F C} C_{F C}=20 \mathrm{~kJ} . \mathrm{K}^{-1}, w_{b} C_{b}$ $=70 \mathrm{~kJ} \cdot \mathrm{K}^{-1}, \Delta H_{H_{2}}=120 \mathrm{MJ} \cdot \mathrm{kg}^{-1}, \eta_{F C}=35 \%, T_{s}=16.8^{\circ} \mathrm{C}$, and $w_{H_{2}}^{p}=0$. We estimate that $\sim 80 \mathrm{~g}$ of buffer $\mathrm{H}_{2}$ capacity is sufficient for FCS start from $-40^{\circ} \mathrm{C}$.

\subsection{Desorption Kinetics}

Not all the intrinsic $\mathrm{H}$-capacity of a storage material may be accessible. For a simple material whose pressure-composition-temperature (PCT) isotherm can be represented by the van't Hoff equation, there is a lower limit of the state-of-charge $(X)$ below which the equilibrium pressure declines rapidly with decrease in $X$. Hydrogen stored below this lower limit is not accessible for release at reasonable back pressures. Similarly, there is an upper limit of the state-of-charge (SOC) above which the equilibrium pressure rises rapidly with increase in $X$. The metal hydride cannot be charged above this upper limit at reasonable refueling pressures. The accessible lower and upper limits of SOC are functions of temperature, and the difference between the two limits for simple metal hydrides becomes smaller at higher temperatures [19].

Chemical kinetics may further limit the usable portion of the accessible intrinsic $\mathrm{H}$ capacity $(\beta)$. Let $X_{\min }$ and $X_{\max }$ denote the kinetically-limited usable minimum and maximum state of charge. The minimum SOC (also called the maximum state of discharge) is determined by the kinetic requirement that the $\mathrm{MH}$ bed should be able to supply the 
minimum full flow of $\mathrm{H}_{2}$ at the lowest operating temperature [15]. Consider a simple representation of the desorption kinetics in which the kinetic rate $\left(\dot{r}_{d}\right)$ is first order in $X$ and $\left(P_{e q}-P\right)$.

$\beta \frac{d X}{d t}=-k_{d} X\left(P_{e q}-P\right)=-\dot{r}_{d}$

For isothermal discharge at constant back pressure $P$, Eq. (5) can be integrated to obtain the following equation for discharge time $\left(\tau_{d}\right)$ between $X_{\max }$ and $X_{\min }$.

$$
\tau_{d}=\left[\frac{\beta}{k_{d}\left(P_{e q}-P\right)}\right] \ln \left(\frac{X_{\text {max }}}{X_{\text {min }}}\right)
$$

Knowing $\tau_{d}$, Eqs. (5) and (6) can be used to determine $X_{\min }$ at which the $\mathrm{H}_{2}$ discharge rate $\left(\dot{w}_{H_{2}}\right)$ from a bed containing $w_{M H}$ amount of MH equals 1.6 g.s $\mathrm{s}^{-1}$ (required minimum full flow rate for an $80-\mathrm{kW}_{\mathrm{e}} \mathrm{FCS}$ ) at the minimum coolant temperature.

$$
X_{\min } \ln \left(\frac{X_{\max }}{X_{\min }}\right)=\frac{\dot{w}_{H_{2}} \tau_{d}}{\beta w_{M H}}
$$

Figure 6 shows the relationship between $\tau_{d}$ and $X_{\min }$ for a bed that contains $5.6 \mathrm{~kg}$ of usable $\mathrm{H}_{2}\left(w_{\mathrm{H}_{2}}\right)$.

$$
\beta\left(X_{\max }-X_{\min }\right) w_{M H}=w_{H_{2}}
$$

Naturally, for given $X_{\max }$, the faster the desorption kinetics, the smaller is $\tau_{d}$, and the lower is the allowable $X_{\min }$.

\subsection{Sorption Kinetics}

Just as the desorption kinetics determines the minimum SOC, the sorption kinetics determines the maximum SOC [15]. The relationship between $X_{\max }$ and the target 3.7-min refueling time is best illustrated by considering, analogous to Eq. (5), a simple representation of the sorption kinetics in which the kinetic rate $\left(\dot{r}_{c}\right)$ is first order in $(1-X)$ and $\left(P-P_{e q}\right)$, and the rate constant $k_{c}$ has Arrhenius dependence on temperature. 
$\beta \frac{d X}{d t}=k_{c}(1-X)\left(P-P_{e q}\right)=\dot{r}_{c}$

$k_{c}=k_{c 0} e^{-E_{c} / R T}$

Because $k_{c}$ increases and $\left(P-P_{e q}\right)$ decreases with increase in temperature, there is an

optimum temperature at which $\dot{r}_{c}$ is the highest. At this optimum refueling temperature $\left(T_{o p}\right)$, the equilibrium pressure $\left(P_{e q}\left(T_{o p}\right)\right)$ is related to the refueling pressure $(P)$ by the following equation.

$P_{e q}\left(T_{o p}\right)=\left(\frac{E_{c} / \Delta H}{1+E_{c} / \Delta H}\right) P$

It follows that the off-board coolant that removes the heat of sorption from the MH tank should always be at a temperature below $T_{o p}$. Figure 7a presents $T_{o p}$ and $P_{e q}\left(T_{o p}\right)$ as a function of refueling pressure for a set of $\Delta H, \Delta S$ and $E_{c}$.

For isothermal refueling at constant pressure, Eq. (9) can be integrated to determine the kinetic refueling time $\left(\tau_{r}\right)$. The actual refueling time will be greater than $\tau_{r}$ due to heat transfer limitations.

$\beta \ln \left(\frac{1-X_{\min }}{1-X_{\max }}\right)=k_{c}\left(P-P_{e q}\right) \tau_{r}$

Taking $\tau_{r}$ as $50 \%$ of the target refueling time, Fig. $7 \mathrm{~b}$ presents the relationship between

$k_{c}$ at $T_{o p}$ and refueling pressure for different $X_{\max }$. It quantifies the levels of $k_{c}\left(T_{o p}\right)$ needed to meet the refueling time target and the enhancement in kinetic rates needed to widen the operating SOC window.

\subsection{Material Compaction and Heat Transfer}

In powder form, metal hydrides and adsorbents have low bulk density and poor thermal conductivity. Meeting the stringent volumetric target requires that the powders be mechanically compacted and consolidated to form pellets and disks. Attention must be paid to allow for the volumetric changes that occur as the material expands upon hydriding and the 
contact resistance between the compact and heat transfer surfaces. The compacts also must possess sufficient permeability for acceptably uniform hydrogen flow during rapid charging so that the MH sorption kinetics is not greatly impaired.

Many methods have been investigated to augment heat transfer in metal hydride beds, including the use of metal foams, wires and fins [30, 31]. Densified metal hydride compacts with high conductivity materials, such as aluminum powder and expanded natural graphite (EG), as additives appear particularly promising. Sanchez et al [31] have shown that the measured effective thermal conductivity $\left(\lambda_{\text {eff }}\right)$ of these compacts can be correlated by a simple model with parallel thermal resistances of metal hydride and the enhanced heat transfer additive.

$$
\lambda_{\text {eff }}=\varepsilon_{M H} \lambda_{M H}+\varepsilon_{E G} \lambda_{E G}
$$

In the above equation, $\varepsilon$ is the material fill factor and it can be represented in terms of the mass fractions $(Y)$, material densities, and the bulk density $\left(\rho_{b}\right)$ of the bed composed of these compacts.

$$
\begin{aligned}
& \varepsilon_{M H}=Y_{M H}\left(\frac{\rho_{b}}{\rho_{M H}}\right) \\
& \varepsilon_{E G}=Y_{E G}\left(\frac{\rho_{b}}{\rho_{E G}}\right) \\
& \varepsilon=\varepsilon_{M H}+\varepsilon_{E G}
\end{aligned}
$$

Figure 8 presents $\lambda_{\text {eff }}$ of a compact with $\lambda_{M H}=1.74 \mathrm{~W} \cdot \mathrm{m}^{-1} \cdot \mathrm{K}^{-1}$ and $\lambda_{E G}=150 \mathrm{~W} \cdot \mathrm{m}^{-1} \cdot \mathrm{K}^{-}$

${ }^{1}$. It shows that the effective thermal conductivity can be improved considerably by increasing the fill factor, i.e., by densifying the powder. However, $>10 \%$ of expanded natural graphite is needed if it is desired that the bed have thermal conductivity higher than $7.5 \mathrm{~W} \cdot \mathrm{m}^{-1} \cdot \mathrm{K}^{-1}$ at a reasonable fill ratio of 0.75 .

The existing data for metal hydrides suggest that there may be a correlation between the material density of metal hydrides (i.e., crystal structure) and their H-capacity [32 - 34]. The 
data in Fig. 9 indicate that $\rho_{M H}$ is smaller for metal hydrides with higher $\beta$; as these are the materials that contain low molecular weight elements, lithium and boron. In the balance of this study, this relationship between $\rho_{M H}$ and H-capacity, as represented by the solid line that is least-squares fit of the data in Fig. 9, is assumed to hold.

\section{Reverse Engineering: A Case Study}

The concepts presented in Section 2 can be employed to determine the envelope of material properties needed to satisfy the system level targets listed in Table 1 . The case study discussed in this section pertains to a low-temperature metal-hydride hydrogen storage system that is thermally integrated with the FCS, as shown schematically in Fig. 1a. The storage system uses the FCS coolant to supply heat during discharge and an off-board coolant to remove heat liberated during refueling. There is no $\mathrm{H}_{2}$ burner in the system so that the onboard storage system efficiency is $100 \%$. Consistent with the discussion in the previous section, the scope of this study is limited to a Type 3 containment tank, buffer $\mathrm{H}_{2}$ tank for FCS start-up from $-40^{\circ} \mathrm{C}$ ambient and system temperature, and expanded natural graphite for thermal conductivity enhancement. Table 3 lists the reference values of coolant temperatures, $\mathrm{MH} \Delta H, \Delta S$ and $E_{c}$, and $Y_{E G}$ considered in this study. Table 3 also includes the specifications for minimum delivery pressure and refueling pressure, and the targets for system gravimetric and volumetric capacities.

\subsection{MH Refueling: Temperature Profile and Conversion}

An important aspect of designing metal hydride tanks is heat removal during fast refueling with compressed hydrogen. A dynamic model is needed to track the temperature profile and hydrogen uptake, both of which change continuously with time during refueling. Consider a unit annular cell of outer radius $r_{2}$ that consists of a representative heat transfer tube of radius $r_{1}$ surrounded by MH-EG compact. Assuming that the gas and solid are in local equilibrium, 
the following equations describe the dynamic changes in temperature and conversion (stateof-charge).

$$
\begin{aligned}
& \rho_{b} C_{b} \frac{\partial T}{\partial t}=\frac{\lambda_{e f f}}{r} \frac{\partial}{\partial r}\left(r \frac{\partial T}{\partial r}\right)+\rho_{b}^{M H} \dot{r}_{c}\left(\frac{\Delta H}{M_{H_{2}}}\right) \\
& \beta \frac{d X}{d t}=k_{c}(1-X)\left(P-P_{e q}\right)=\dot{r}_{c} \\
& -\lambda_{\text {eff }} \frac{\partial T}{\partial r}=h\left(T_{1}-T\right) \text { at } r=r_{1} \\
& \frac{\partial T}{\partial r}=0 \text { at } r=r_{2}
\end{aligned}
$$

where $r$ is the radial coordinate, $t$ is the time, $\rho_{b}^{M H}$ is the bulk density of $\mathrm{MH}, M$ is the molecular weight, $h$ is the coolant-side convective heat transfer coefficient, and $T_{1}$ is the temperature of the coolant. Equations (17) - (19) were solved numerically using an implicit finite difference scheme with the spatial derivative (heat conduction term) discretized by central differencing.

The finite-difference model was used to run a set of simulations designed to investigate the effect of off-board coolant temperature on refueling at constant pressure $(P=$ $100 \mathrm{~atm}$ ), starting from $T=T_{1}$ and $X=X_{\min }=0.1$, and using the values of $\Delta H, \Delta S, E_{c}$ and $Y_{E G}$ listed in Table 3 and the kinetic constant $k_{c}$ for sorption estimated from Eq. (12). The size of the unit cell was determined iteratively to achieve complete refueling, defined as average $X=0.9$, in $3.7 \mathrm{~min}\left(t_{r}\right)$. Figure 10 summarizes the results from these simulations. The results indicate that even with EG additive the $\lambda_{\text {eff }}$ is low, and in the short refueling time (i.e., sorption kinetics is fast and the heat release rate is high), the unit cell periphery heats up rapidly, overshoots the optimum temperature well within $t / t_{r}=0.2$, and then approaches the equilibrium temperature corresponding to $100 \mathrm{~atm}$ refueling pressure. At longer times, the unit cell actually cools because of the heat removed by the coolant and the slowing 
exothermic absorption reaction. The bed temperature profile evolves continuously during the refueling process, i.e., a steady-state temperature profile is not established.

Figure 10 shows that the conversion $\left(X_{2}\right)$ at cell periphery $\left(r=r_{2}\right)$ is the slowest and that it is limited more by heat transfer rather than by sorption kinetics. At $60^{\circ} \mathrm{C}$ initial and coolant temperature, the maximum conversion occurs at a non-dimensional distance of 0.22 at $t / t_{r}=0.2$; with time, the point of maximum conversion tracks the location of $T_{o p}\left(\sim 87^{\circ} \mathrm{C}\right)$ and slowly moves farther out from the heat exchanger tube. At $90^{\circ} \mathrm{C}$ coolant temperature, the maximum conversion occurs at the surface of the heat exchanger tube and it does not move with time as the bed temperatures are higher than $T_{o p}$.

\subsection{System Analysis Methodology}

In an earlier publication [15], we described a system model to analyse the performance of low-temperature metal hydride systems. In this work, we modified it to incorporate the unitcell transient reaction and heat transfer model discussed in Section 3.1. The method of using this updated model to conduct reverse engineering analysis is discussed below.

As indicated in Tables 3 and 4, we assume that the following variables are specified: material thermodynamic properties $\left(\Delta H, \Delta S, E_{c}\right)$; minimum and maximum limits of SOC $\left(X_{\min }, X_{\max }\right)$; on-board and off-board coolant temperatures; refueling pressure; heat transfer tube parameters (aluminium, tube diameter, tube thickness); EG weight fraction $\left(Y_{E G}\right)$; weight and volume of the balance-of-plant (BOP) components (pumps, valves, piping, etc.); and $\mathrm{H}_{2}$ collection and distribution system (five stainless-steel sintered metal tubes).

The following are the target performance parameters to be determined from the reverse engineering analysis: charge kinetic rate; discharge kinetic rate; bulk density of MH/EG composites; number of heat transfer tubes; liner thickness; CF composite thickness; vessel diameter, vessel length; and the amount of buffer $\mathrm{H}_{2}$ and weight/volume of buffer tank. 
The reverse engineering analysis is conducted subject to the following constraints that must be satisfied: amount of usable $\mathrm{H}_{2}$; system gravimetric capacity; system volumetric capacity; minimum full flow rate of $\mathrm{H}_{2}$; refueling time; start-up from cold; SAE code for liner fatigue; SAE code for burst safety factor; and vessel aspect ratio (study parameter).

There is not a one-to-one correspondence between the performance parameters and the constraints. For example, bulk density affects both the volumetric capacity and the thermal conductivity and hence the refueling time. A multidimensional non-linear equation solver is needed and one based on steepest descent method with quasi-Newton update has been found to be particularly suitable. The challenge was to embed, within the iteration loop of the equation solver, the finite-difference algorithm discussed in Section 3.1 for determining the temperature profile, conversion and refueling time.

\subsection{Reference Material Properties}

Table 4 lists the reference material properties needed to satisfy the system targets as determined using the system model outlined in Section 3.2. The system model indicates that a prospective $\mathrm{MH}$ candidate should have greater than $13.5 \%$ accessible intrinsic $\mathrm{H}$-capacity ( $\beta$ ) for the system to have $5.5 \mathrm{wt} \%$ gravimetric capacity. When mixed with $10 \%$ expanded natural graphite, the metal hydride should be capable of being compacted to $589 \mathrm{~kg} \cdot \mathrm{m}^{-3}$ ( $\rho_{b}^{M H}$ ) for the system to reach 40 g.L $\mathrm{L}^{-1}$ volumetric capacity. The resulting MH/EG compact in the fully-hydrided state has $24.7 \%$ bed porosity and $8.4 \mathrm{~W} \cdot \mathrm{m}^{-1} \cdot \mathrm{K}^{-1}$ thermal conductivity. The 3.7-min refueling time target can be met if the rate constant for charge kinetics is greater than 4.2 g. $(\mathrm{kg}-\mathrm{MH})^{-1} \cdot \mathrm{min}^{-1} \cdot \mathrm{atm}^{-1}$ for isothermal refueling at the optimum temperature corresponding to 100 -atm back pressure. The $1.6 \mathrm{~g} . \mathrm{s}^{-1}$ full flow rate requirement can be met if the metal hydride can be discharged from an SOC of 0.9 to 0.1 in $\leq 16.8 \mathrm{~min}$ at $60^{\circ} \mathrm{C}$ and 5atm back pressure. 
As indicated in Table 4, $85 \mathrm{U}$ tubes are needed for circulating the off-board coolant at $80^{\circ} \mathrm{C}$ and charging the $\mathrm{MH}$ tank at $1.5 \mathrm{~kg} \cdot \mathrm{min}^{-1}$ refueling rate. The mean spacing between the tubes is 3.1 times the tube diameter. The tank needs to be loaded with $51.2 \mathrm{~kg}$ of $\mathrm{MH}$ (and 5.1 $\mathrm{kg}$ of EG) for $5.6 \mathrm{~kg}$ usable $\mathrm{H}_{2}$ between $X_{\min }$ and $X_{\max }$.

A 33.7- $\mathrm{L}$ buffer tank capable of storing $80 \mathrm{~g}$ of $\mathrm{H}_{2}$ at $80^{\circ} \mathrm{C}$ and $40 \mathrm{~atm}$ is needed for a single start from $-40^{\circ} \mathrm{C}$. The tank weighs $11.1 \mathrm{~kg}$ if it is made of $\mathrm{Al} 6061-\mathrm{T} 6$ alloy.

Figure 11 presents the weight and volume distribution of an MH storage system that meets all system requirements. It shows that the MH storage medium accounts for $50 \%$ of the overall weight and that $21 \%$ of the weight is due to the heat transfer subsystem that includes $\mathrm{EG}$, the heat transfer fluid and the in-bed heat exchanger tubes. On a volume basis, $\mathrm{MH}$ and the buffer $\mathrm{H}_{2}$ tank are the largest components accounting for $60 \%$ and $24 \%$ of the overall system volume, respectively.

\subsection{Sensitivity Study}

The reference material targets in the above section were based on certain assumptions regarding the off-board coolant temperature, refueling pressure, EG to $\mathrm{MH}$ weight ratio, and minimum and maximum states-of-charge. This section briefly discusses the effect of relaxing these assumptions.

Figure 12a summarizes the results from a sensitivity study on the effect of off-board coolant temperature on the target accessible $\mathrm{H}$-capacity of the $\mathrm{MH}$. It shows that for an $\mathrm{MH}$ with $\Delta H, \Delta S$ and $E_{c}$ listed in Table $4, \operatorname{target} \beta$ is smaller if the coolant temperature is lowered to $60^{\circ} \mathrm{C}$ from $80^{\circ} \mathrm{C}$. This is due to the higher heat rejection rate at $60^{\circ} \mathrm{C}$ and the resulting saving in weight as fewer heat exchanger tubes are needed. The simulation results clearly indicate that conversion is limited by heat transfer if the sorption kinetics is sufficiently fast to meet the $1.5 \mathrm{~kg} \cdot \mathrm{min}^{-1}$ refueling rate target. 
Figure $12 \mathrm{~b}$ summarizes the results from a sensitivity study on the effect of refueling pressure on $\beta$. We find that $\beta$ is lowest at $100-110$ atm refueling pressure. At higher refueling pressures, $\beta$ has to be larger to compensate for the heavier liner and CF composite. Also, at lower refueling pressures, $T_{o p}$ is lower (see Eq. (11)), and more heat transfer tubes are needed to maintain the bed at a lower temperature during refueling.

Figure $12 \mathrm{c}$ summarizes the results from a sensitivity study on the effect of EG to MH weight ratio on $\beta$. The study shows that an EG to MH weight ratio of 0.1 is about the optimum. The effective thermal conductivity increases at higher EG to MH ratio but the added weight of EG is greater than the resulting saving in the weight of the heat transfer tubes.

Figure 13a summarizes the results from a sensitivity study on the effect of desorption kinetics, $k_{d}$, on material targets. Doubling $k_{d}$ (same as halving $\tau_{d}$ ) from the reference value lowers $X_{\min }$ to 0.05 from 0.1 and results in a small decrease (beneficial) in the needed $\beta$; this decrease is proportional to $\left(X_{\max }-X_{\min }\right)$. However, a $50 \%$ reduction in $k_{d}$ results in a larger increase (penalty) in the needed $\beta$.

Finally, Fig. 13b summarizes the results from a sensitivity study on the effect of sorption kinetics, $k_{c}\left(T_{o p}\right)$, on the material targets. Doubling $k_{c}$ from the reference value raises $X_{\max }$ to $\sim 1$ from 0.9 while lowering $X_{\min }$ to 0.06 from 0.1 , and results in an $11 \%$ decrease in $\beta$. However, a $50 \%$ decrease in $k_{c}$ lowers $X_{\max }$ to 0.52 (with an accompanying small increase in $\left.X_{\min }\right)$ and results in $>63 \%$ increase (penalty) in the needed $\beta$.

\section{Discussion of Results}

We have developed an integrated model to determine the bounding thermodynamic, physical, kinetic and thermal requirements for on-board hydrogen storage in reversible, lowtemperature metal hydrides. 
The thermodynamic requirements have been defined as a relationship between $\Delta H$ and $\Delta S$ for simple metal hydrides for which the plateau pressure can be represented by a single van't Hoff equation. The acceptable $\Delta H$ for these simple materials should be between the upper and lower limits identified in Fig. 3a as a function of $\Delta S$. This thermodynamic requirement also applies to all the absorption/desorption steps in more complex materials that store and release $\mathrm{H}_{2}$ through multiple reaction pathways. The underlying requirement is that the equilibrium pressure should be greater than 5 atm at the minimum FCS coolant temperature $\left(60^{\circ} \mathrm{C}\right.$ in this study) for at least one desorption step and less than 100 atm at 100 $150^{\circ} \mathrm{C}$ for all adsorption steps.

This study has determined that the intrinsic hydrogen capacity, i.e., the material gravimetric capacity, accessible between 5 and 100 atm at $60-150^{\circ} \mathrm{C}$, should be higher than $13.5 \mathrm{wt} \%$. The volumetric capacity (product of bulk density and gravimetric capacity), accessible between the same range of operating pressures and temperatures, should be higher than $80 \mathrm{~kg}-\mathrm{H}_{2} \cdot \mathrm{m}^{-3}$-sorbent.

The desorption kinetic requirement has been defined in terms of the time to discharge the metal hydride between a range of the state-of-charge at $60^{\circ} \mathrm{C}$ and 5-atm back pressure. Meeting this requirement ensures that the system can supply $\mathrm{H}_{2}$ at $1.6 \mathrm{~g} / \mathrm{s}$ minimum full flow rate over the complete range of operating pressures, temperatures and SOC $(X)$. Although the discharge time was determined for a simple hydride with specified $\Delta H$ and $\Delta S$ and desorption kinetics that is first-order in $X$ and $\left(P-P_{e q}\right)$, the 17-min recommended value for $\tau_{d}$ may be used as an initial guide for more complex materials that may follow a different desorption kinetic pathway.

Our analysis indicates that a candidate material should be capable of being charged isothermally from $10 \%$ to $90 \%$ of the accessible intrinsic capacity within 1.85 min at constant 100 -atm and any temperature between 60 and $150^{\circ} \mathrm{C}$. The proposed kinetic time is half of the 
system target for refueling time to allow for heat transfer limitations. A detailed transient model that considers reaction kinetics and temperature distribution supports the simpler methodology used in developing the criterion for sorption kinetics. As above, although the charging time was determined for a simple hydride with specified $\Delta H$ and $\Delta S$ and sorption kinetics that is first-order in $(1-X)$ and $\left(P-P_{e q}\right)$, the 1.85-min recommended value for $\tau_{c}$ may be used as an initial guide for more complex materials that may follow a different sorption kinetic pathway.

Since metal hydride powders have low thermal conductivity, they must be compacted and mixed with high conductivity materials, such as aluminium and expanded natural graphite, to augment heat transfer characteristics. This study suggests a minimum effective thermal conductivity of $8.4 \mathrm{~W} \cdot \mathrm{m}^{-1} \cdot \mathrm{K}^{-1}$ as a reasonable target for the metal hydride compact. The heat transfer additive to metal hydride weight ratio preferably should be less than 0.1 .

Whereas the foregoing material requirements are extremely stringent in isolation, the bigger challenge is to meet them simultaneously. In spite of several decades of intensive material research on an international scale, no metal hydride capable of meeting these requirements has been identified, let alone verified $[1,2,4]$. Fundamental research is urgently needed to identify and develop high capacity materials that can be thermodynamically destabilized and catalyzed to absorb and release hydrogen in the range of operating temperatures and pressures and at rates indicated in Table 4.

The results of this study compliment the earlier work by Pasini et al [33] who concluded that the low-temperature metal hydrides need to have 11 wt\% gravimetric capacity, somewhat lower than $13.5 \mathrm{wt} \%$ suggested by us. There are two main reasons that may account for this difference. First, Ref. [33] assumes that Type 4 tanks with a polymer liner can be used for service at temperatures above $120^{\circ} \mathrm{C}$. We follow the SAE J2579 guideline that limits high-density polyethylene (HDPE) plastic liner to excursions at temperatures 
exceeding $80^{\circ} \mathrm{C}$. Second, we include a hydrogen buffer tank for start-up from cold and provide sufficient capacity for a single start from $-40^{\circ} \mathrm{C}$. Ref. [33] does not specifically discuss the rationale for excluding the buffer tank in their analysis.

\section{$5 \quad$ Summary and Conclusions}

Automotive duty cycles impose some unique and stringent requirements on on-board hydrogen storage systems. These requirements can be used to derive certain minimum material properties that metal hydrides must have to be viable candidates for the automotive application. The following is a summary of the minimum thermodynamic, physical, kinetic and thermal requirements for prospective metal hydrides.

a) The equilibrium pressure should be greater than $5 \mathrm{~atm}$ at the minimum FCS coolant temperature $\left(60^{\circ} \mathrm{C}\right.$ in this study) and less than 100 atm at $100-150^{\circ} \mathrm{C}$.

b) The intrinsic hydrogen capacity $(\beta)$, accessible between 5 and 100 atm at $60-150^{\circ} \mathrm{C}$, should be higher than $13.5 \mathrm{wt} \%$ (135 $\mathrm{g}-\mathrm{H}_{2}$ per $\left.\mathrm{kg}\right)$.

c) The material should discharge from $90 \%$ to $10 \%$ of the accessible intrinsic capacity in $<17$ min at the minimum FCS coolant temperature and 5-atm back pressure.

d) The material should be capable of being charged isothermally from $10 \%$ to $90 \%$ of the accessible intrinsic capacity within $1.85 \mathrm{~min}$ at constant 100 -atm. The charge temperature can be between 60 and $150^{\circ} \mathrm{C}$.

e) All properties should be measured on samples prepared by mixing the metal hydride with a high conductivity material (such as expanded natural graphite) and after compacting the sample to $600 \mathrm{~kg} \cdot \mathrm{m}^{-3} \mathrm{MH}$ bulk density. The compact should have a minimum effective thermal conductivity of $8.4 \mathrm{~W} \cdot \mathrm{m}^{-1} \cdot \mathrm{K}^{-1}$. The heat transfer additive to metal hydride weight ratio preferably should be less than 0.1 . 


\section{Acknowledgements}

This work was supported by the Fuel Cell Technologies Office of the U.S. Department of Energy's (DOE) Office of Energy Efficiency and Renewable Energy. Ms. Grace Ordaz was the DOE Technology Development Manager for this work. Argonne is a DOE, Office of Science Laboratory operated under Contract No. DE-AC02-06CH11357 by UChicago, Argonne, LLC.

\section{References}

1 Klebanoff L and Keller J, Final Report for the DOE Metal Hydride Center of Excellence. Sandia Report SAND2012-0786, 2012.

2 Bowman B and Klebanoff L, Historical Perspectives on Hydrogen, Its Storage, and Its Applications, Chapter 3 in Hydrogen Storage Technology: Material and Applications. CRC Press. ISBN-13: 978-1439841075, 2012.

3 Sandrock G, A Panoramic Overview of Hydrogen Storage Alloys from a Gas Reaction Point of View, J. Alloys and Compounds 1999; 877: 293-295.

4 Klebanoff L and Keller J, 5 Years of hydrogen research in the U.S. DOE Metal Hydride Center of Excellence (MHCoE). Int. J. Hydrogen Energy 2013; 38: 4533-4576.

5 Ahluwalia R, Hua T, and Peng J, Automotive Storage of Hydrogen in Alane. Int. J. Hydrogen Energy 2009; 34: 7731-7740.

6 Graetz J, Reilly J, Kulleck, J and Bowman Jr., R, Thermodynamics and Kinetics of the Aluminum Hydride Polymorphs. J. Alloys Compd. 2007, 446-447: 271-275.

7 Zidan R, Garcia-Diaz B, Fewox C, Stowe A, Grey J and Harte A, Chem. Commun. 2009; $25: 3717$

8 Ahluwalia R, Peng J, and Hua T, Hydrogen Release from Ammonia Borane Dissolved in an Ionic Liquid, Int. J. Hydrogen Energy 2011; 36: 15698-15697. 
9 Ott K, Final Report for the DOE Chemical Hydrogen Storage Center of Excellence, Los Alamos Report LA-UR-20074, 2010.

10 Keaton R, Blacquiere $\mathrm{J}$ and Baker R, Base Metal Catalyzed Dehydrogenation of Ammonia-Borane for Chemical Hydrogen Storage. J. Am. Chem. Soc., 2007; 129:1844.

11 Hua T and Ahluwalia R, Alane Hydrogen Storage for Automotive Fuel Cells - OffBoard Regeneration Processes and Efficiencies, Int. J. Hydrogen Energy 2011; 36: $15259-15265$.

12 Hua $\mathrm{T}$ and Ahluwalia R, Off-board Regeneration of Ammonia Borane for Use as a Hydrogen Carrier for Automotive Fuel Cells, Int. J. Hydrogen Energy 2012; 37: 1438214392.

13 Sutton A, Burrell A, Dixon D, Garner E, Gordon J, Nakagawa T, Ott K and Vasiliu M, Regeneration of Ammonia Borane by Direct Reaction with Hydrazine and Liquid Ammonia, Science 2011; 331: 1426.

14 Go/No-Go Recommendation for Sodium Borohydride for On-Board Vehicular Hydrogen Storage. Independent Review 2007, available at http://www1.eere.energy.gov/hydrogenandfuelcells/pdfs/42220.pdf.

15 Ahluwalia R, Sodium Alanate Hydrogen Storage System for Automotive Fuel Cells, Int. J. Hydrogen Energy 2007; 32: 1251-1261.

16 Ahluwalia R, Wang X, Kwon J, Rousseau A, Kalinoski J, James B, and Marcinkoski J, Performance and Cost of Automotive Fuel Cell Systems with Ultra-low Platinum Loadings, J. Power Sources 2011; 196: 4619-4630.

17 Ahluwalia R and Wang X, Fuel Cell Systems for Transportation: Status and Trends, J. Power Sources 2008; 177: 167-176. 
18 DOE Targets for On-Board Hydrogen Storage Systems for Light-Duty Vehicles, February 2014, published on DOE/FCT website: http://energy.gov/sites/prod/files/2014/03/f12/targets_onboard_hydro_storage.pdf.

19 Schlapbach L and Zuttel A, Hydrogen Storage Materials for Mobile Application, Nature 2001; 414: 353-358.

20 Hydrogen Storage Materials Database - Hydride Information Center (Hydpark) http://hydrogenmaterialssearch.govtools.us/Search.aspx.

21 Hua T, Ahluwalia R, Peng J, Kromer M, Lasher S, McKenney K, Law K, and Sinha J, Technical Assessment of Compressed Hydrogen Storage Tank Systems for Automotive Applications. Int. J. Hydrogen Energy 2011; 36: 3037-3049.

22 T700S DATA SHEET - Toray Carbon Fibers America. www.toraycfa.com/pdfs/t700sdatasheet.pdf, 2013.

23 Simulia Inc. ABAQUS analysis user's manual; 2011.

24 Roh H, Hua T, and Ahluwalia R, (2013) Optimization of carbon fiber usage in Type 4 hydrogen storage tanks for fuel cell automobiles, Int. J. Hydrogen Energy 2013; 38: $12705-12802$.

25 Zickel J, Isotensoid Pressure Vessels, ARS J. 1962; 32: 950-951.

26 Vasiliev V and Morozov E, Mechanics and Analysis of Composite Materials. New York: Elsevier, 2001.

27 Peter S, Humphrey W, and Foral R, Filament Winding: Composite Structure Fabrication. California: SAMPE, 1991.

28 Ahluwalia R, Hua T, and Peng J, On-board and Off-board Performance of Hydrogen Storage Options for Light-Duty Vehicles, Int. J. Hydrogen Energy 2012; 37: 2891-2910.

29 SAE J2579, Technical Information Report for Fuel Systems in Fuel Cell and Other Hydrogen Vehicles. SAE International, 2013. 
30 Ranong $\mathrm{C}$ et al, Concept, Design and Manufacture of a Prototype Hydrogen Storage Tank Based on Sodium Alanate. Chem. Eng. Tech. 2009; 32 (8): 1154-1163.

31 Sanchez A, Klein H, and Groll M, Expanded Graphite as Heat Transfer Matrix in Metal Hydride Beds. Int. J. Hydrogen Energy 2003; 28: 515-517.

32 Van Hassel B, Mosher D, Pasini J, Gorbounov M, Holowczak J, Tang X, Brown R, Laube B, and Pryor L, Engineering Improvement of $\mathrm{NaAlH}_{4}$ System, Int. J. Hydrogen Energy 2012; 37: 2756-2766.

33 Pasini J, Corgnale C, Van Hassel B, Motyka T, Kumar S, and Simmons K, Metal Hydride Material Requirements for Automotive Hydrogen Storage System, Int. J. Hydrogen Energy 2013; 38: 9755-9765.

34 Pasini J, Van Hassel B, Mosher D and Veenstra M, (2012) System Modeling Methodology and Analyses for Materials-Based Hydrogen Storage. Int. J. Hydrogen Energy 2012; 37: 2874-2884. 
Figure Captions

Figure 1: Thermal integration of LTMH and MTMH storage systems with low-temperature fuel cell systems

Figure 2: Conceptual automotive fuel cell system with compressed hydrogen storage tank. The symbols in 2(b) denote the range of possible FCS coolant exit temperatures.

Figure 3: Thermodynamic requirement of metal hydrides suitable for on-board hydrogen storage

Figure 4: Weight and volume of CF composite and liner in Type-3 containment tank with 95 L internal volume

Figure 5: Integration of buffer $\mathrm{H}_{2}$ tank and $\mathrm{MH}$ bed and buffer capacity needed for cold start Figure 6: Desorption kinetics requirements defined in termed of time to discharge $\mathrm{MH}$ from $X_{\max }$ to $X_{\min }$ at $60^{\circ} \mathrm{C}, 5$-atm back pressure

Figure 7: Sorption kinetics requirements defined by considering isothermal refueling at constant pressure

Figure 8: Effective thermal conductivity of compacts as function of fill factor and EG to MH weight ratio

Figure 9: Correlation between MH material density and intrinsic H-capacity, data from Van Hassel et al [27]

Figure 10: Temperature profile and conversion during refueling from $X_{\min }$ to $X_{\max }$ at constant pressure (100 atm)

Figure 11: Weight and volume distribution for a $\mathrm{H}_{2}$ storage system using a metal hydride with material properties that combine to satisfy all the system-level requirements listed in Table 1 
Figure 12: Single-parameter sensitivity study to examine the effect of off-board coolant temperature, refueling pressure and EG to $\mathrm{MH}$ weight ratio on intrinsic material capacity target

Figure 13: Single-parameter sensitivity study to examine the effect sorption and desorption kinetics on intrinsic material capacity target

Table Captions

Table 1: Technical System Targets for On-board Hydrogen Storage for Light-Duty Fuel Cell Vehicles

Table 2: Properties of T700S Carbon Fiber and Composite (60\% fiber volume)

Table 3: Reverse Engineering Study Parameters

Table 4: Reference Metal Hydride Targets 

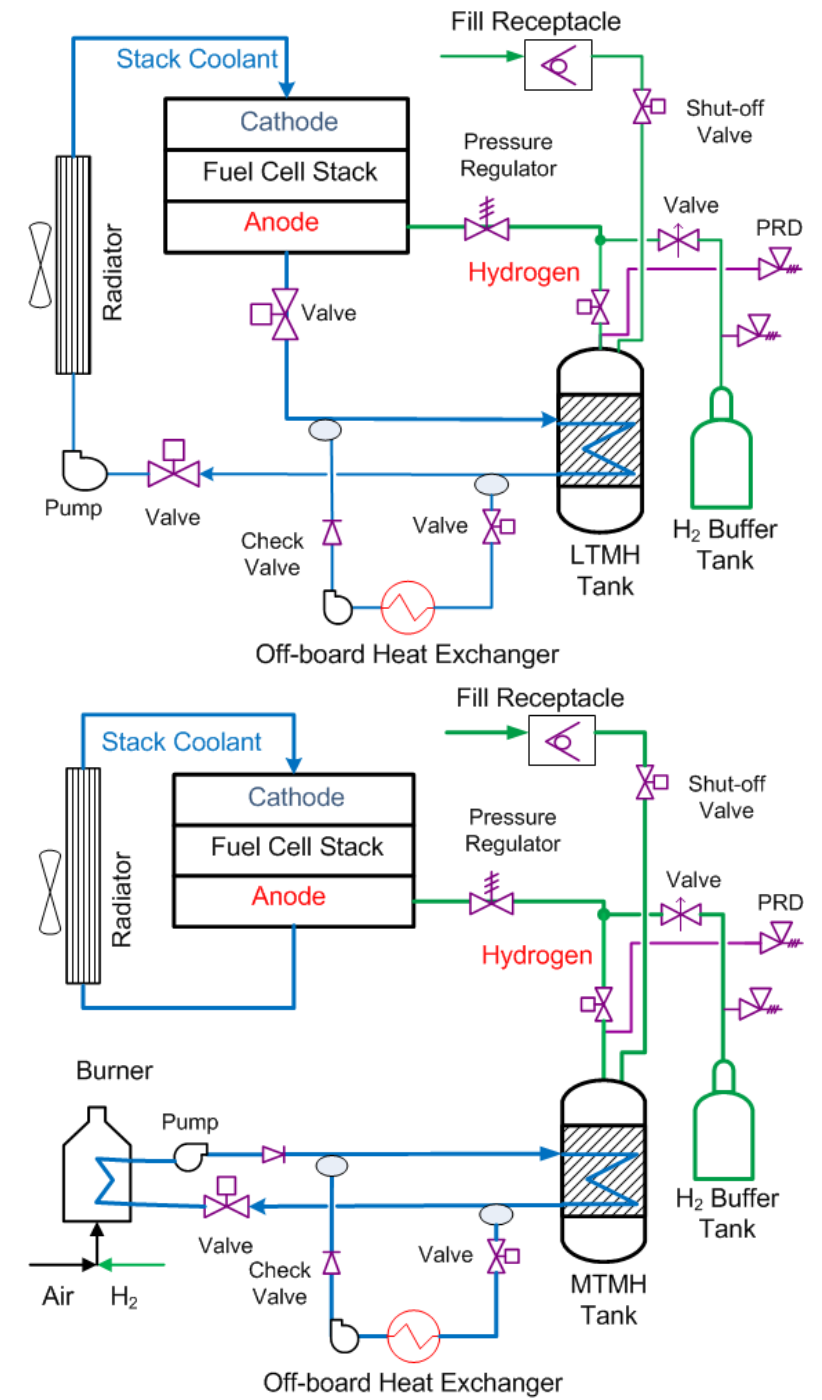

(a) LTMH

(b) MTMH

Figure 1: Thermal integration of LTMH and MTMH storage systems with low-temperature fuel cell systems 

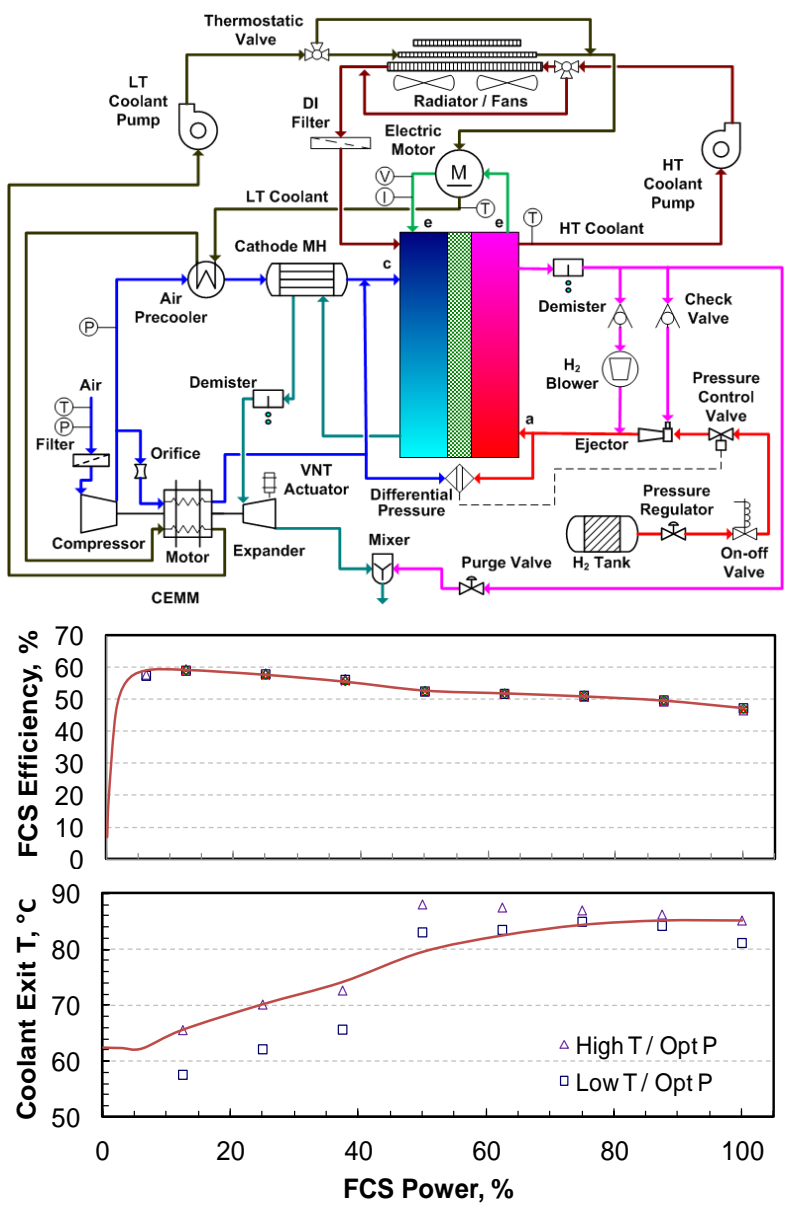

(a) Fuel cell system

(b) Operating temperatures and FCS efficiencies

Figure 2: Conceptual automotive fuel cell system with compressed hydrogen storage tank. The symbols in 2(b) denote the range of possible FCS coolant exit temperatures. 

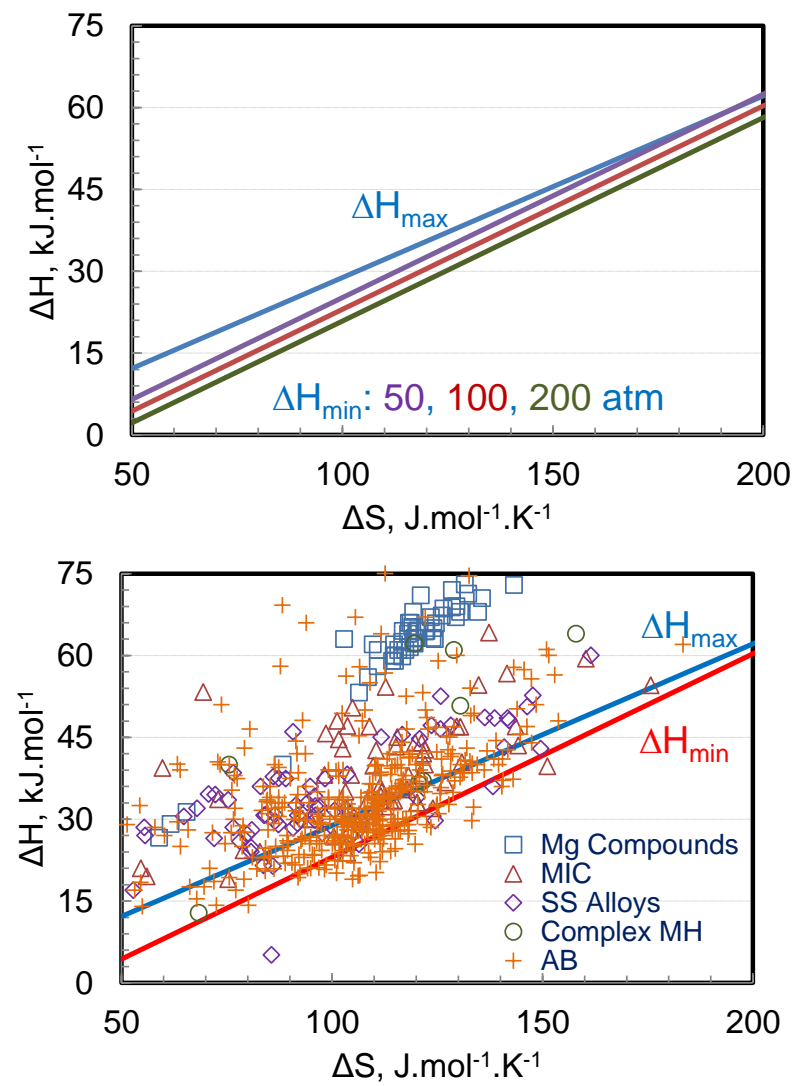

(a) Acceptable enthalpy-entropy relationship (b) $\Delta H-\Delta S$ map of selected metal hydrides Figure 3: Thermodynamic requirement of metal hydrides suitable for on-board hydrogen storage 

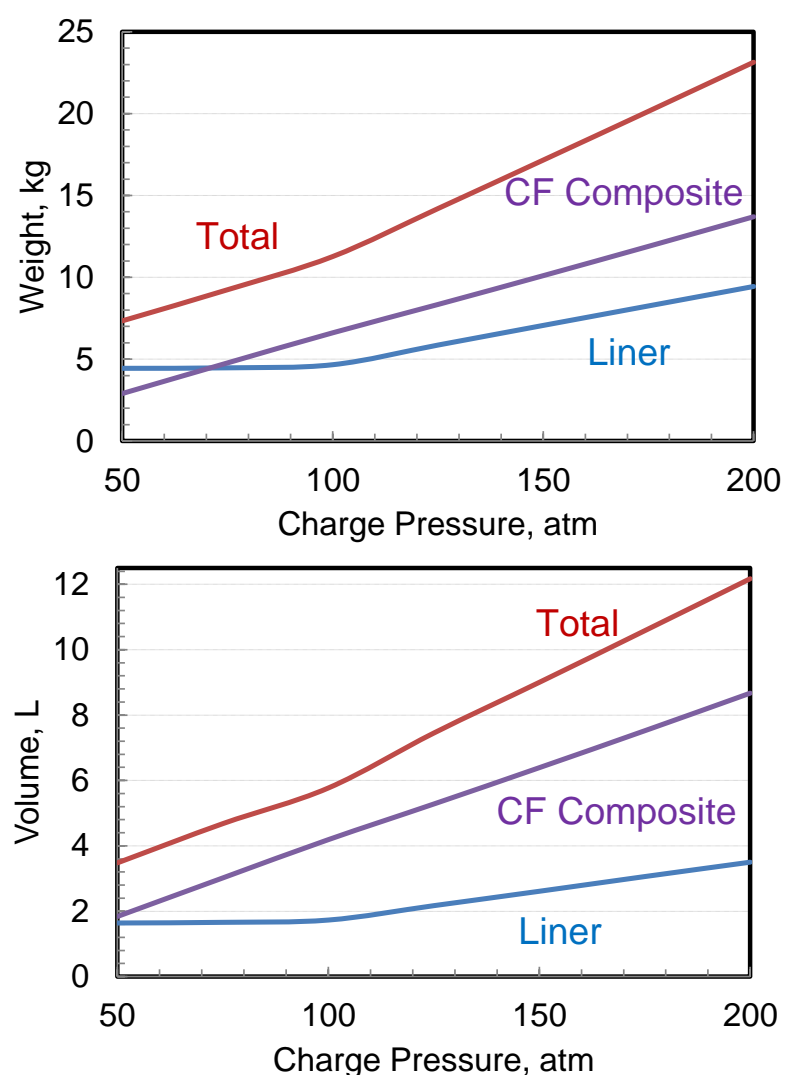

Figure 4: Weight and volume of CF composite and liner in Type-3 containment tank with 95 L internal volume 

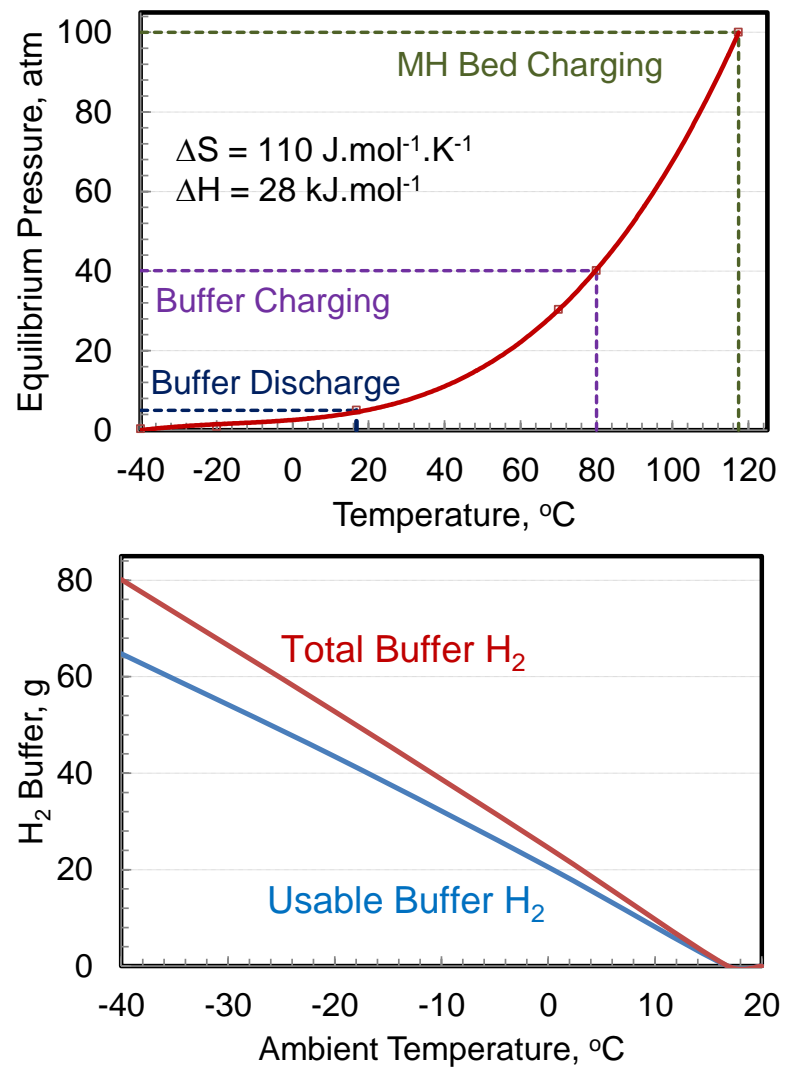

(a) Integration of $\mathrm{H}_{2}$ buffer tank and $\mathrm{MH}$ bed (b) Buffer capacity for single start from cold

Figure 5: Integration of buffer $\mathrm{H}_{2}$ tank and $\mathrm{MH}$ bed and buffer capacity needed for cold start. 


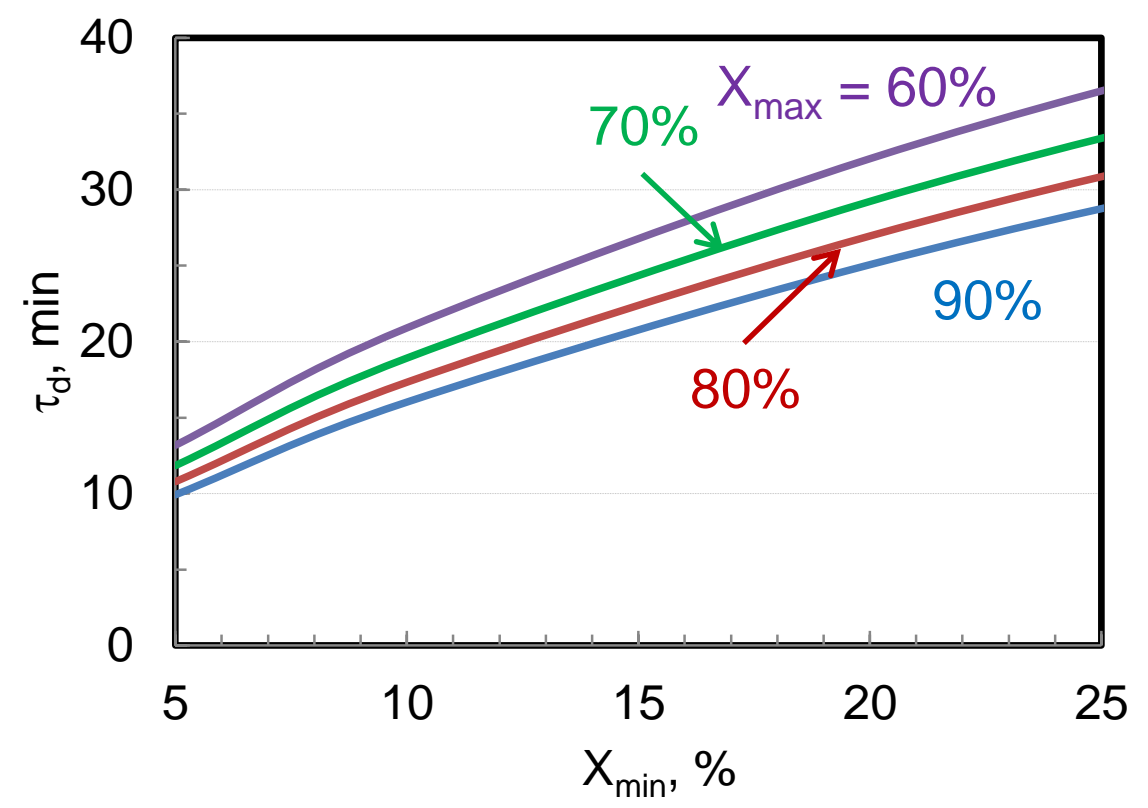

Figure 6: Desorption kinetics requirements defined in termed of time to discharge $\mathrm{MH}$ from $X_{\max }$ to $X_{\min }$ at $60^{\circ} \mathrm{C}, 5$-atm back pressure. 

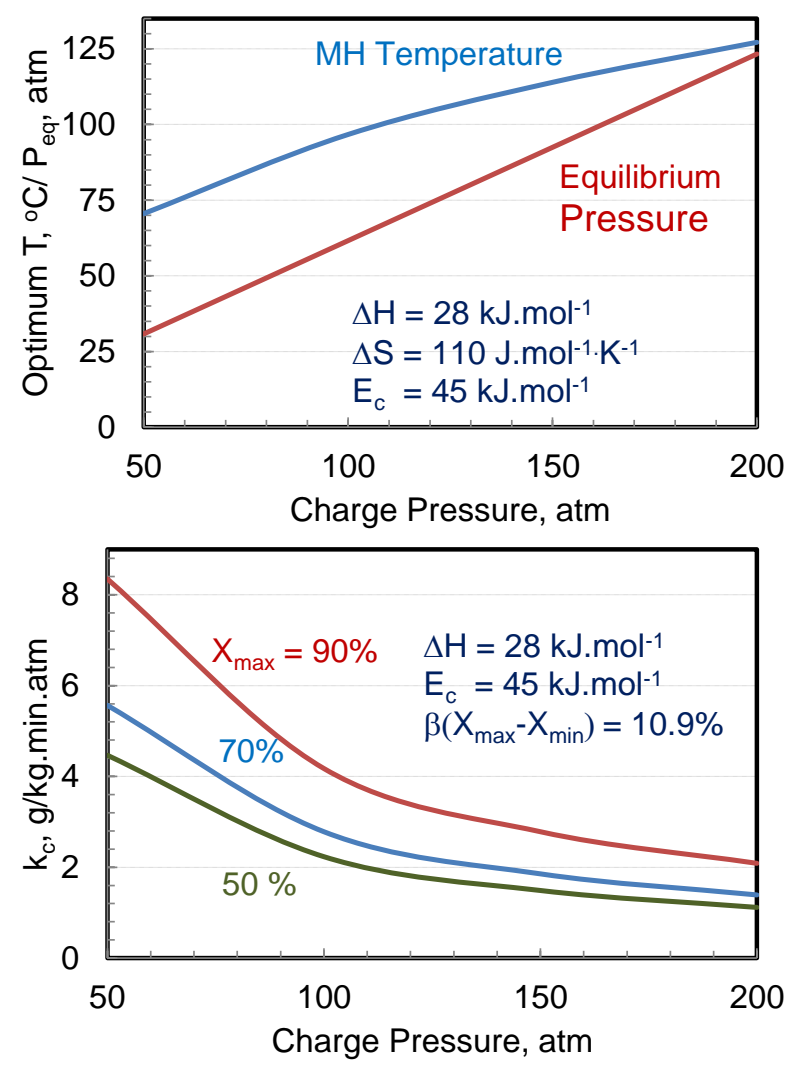
(a) Optimum sorption temperature
(b) Sorption kinetic constant at $\mathrm{T}_{\mathrm{op}}$

Figure 7: Sorption kinetics requirements defined by considering isothermal refueling at constant pressure 


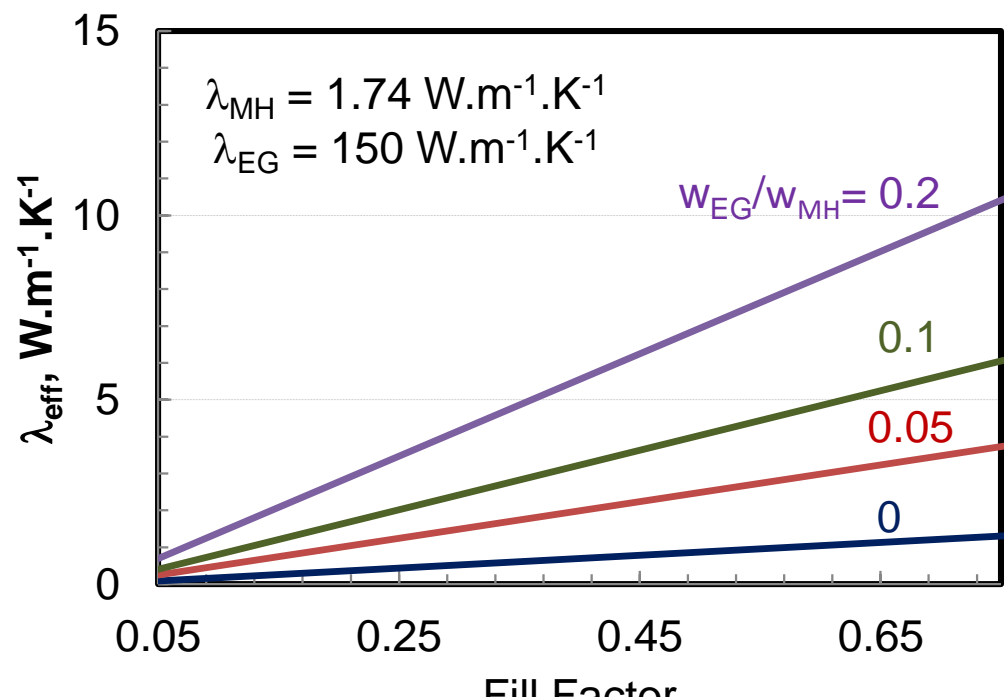

Figure 8: Effective thermal conductivity of compacts as function of fill factor and EG to $\mathrm{MH}$ weight ratio 


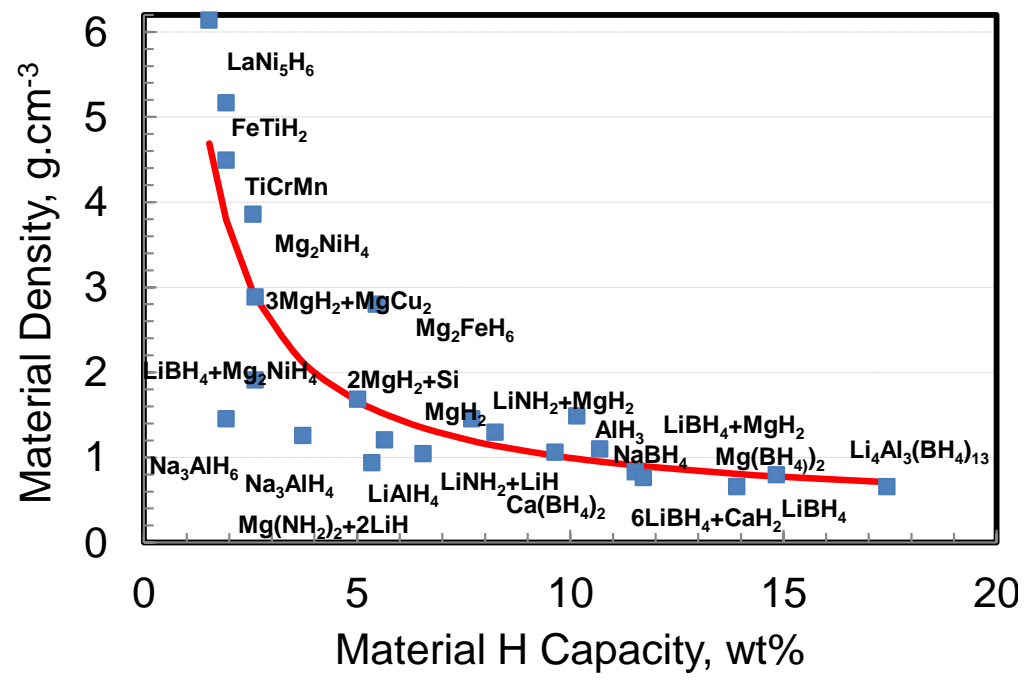

Figure 9: Correlation between MH material density and intrinsic H-capacity, data from Van Hassel et al [27] 

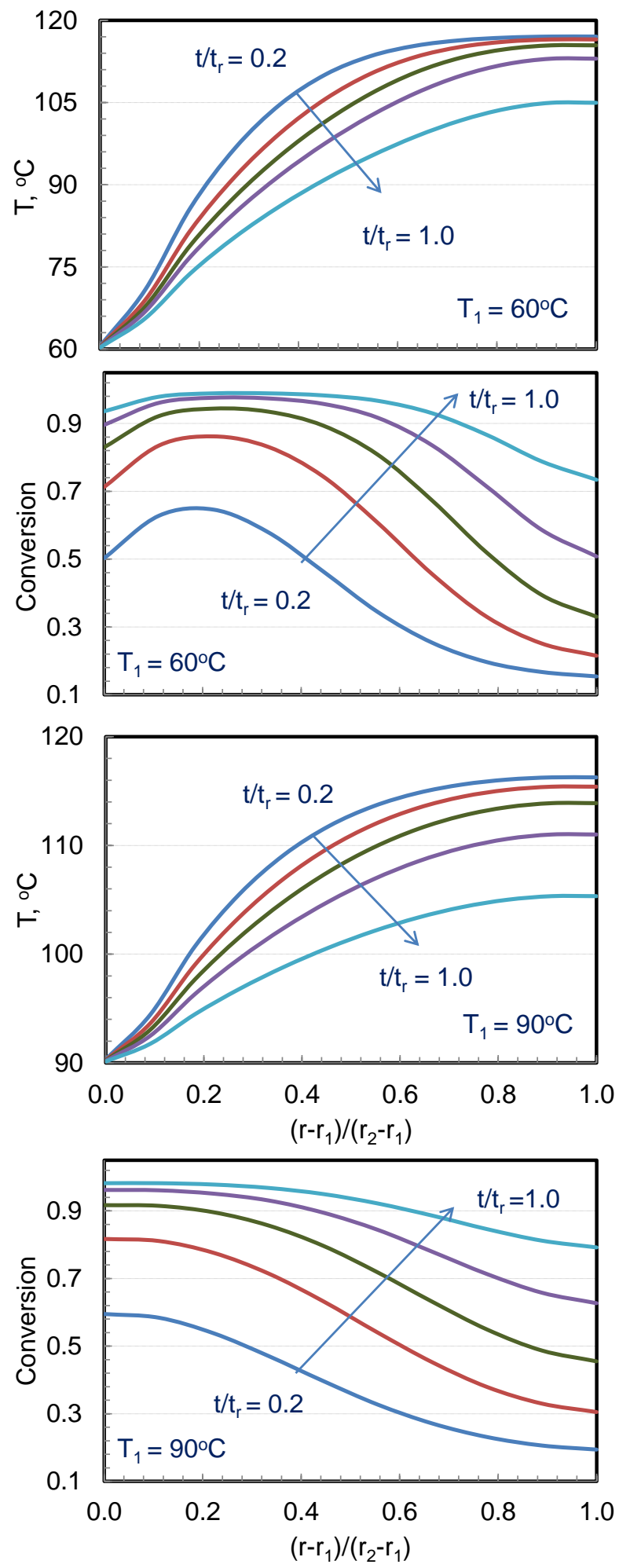

Figure 10: Temperature profile and conversion during refueling from $X_{\min }$ to $X_{\max }$ at constant pressure (100 atm) 


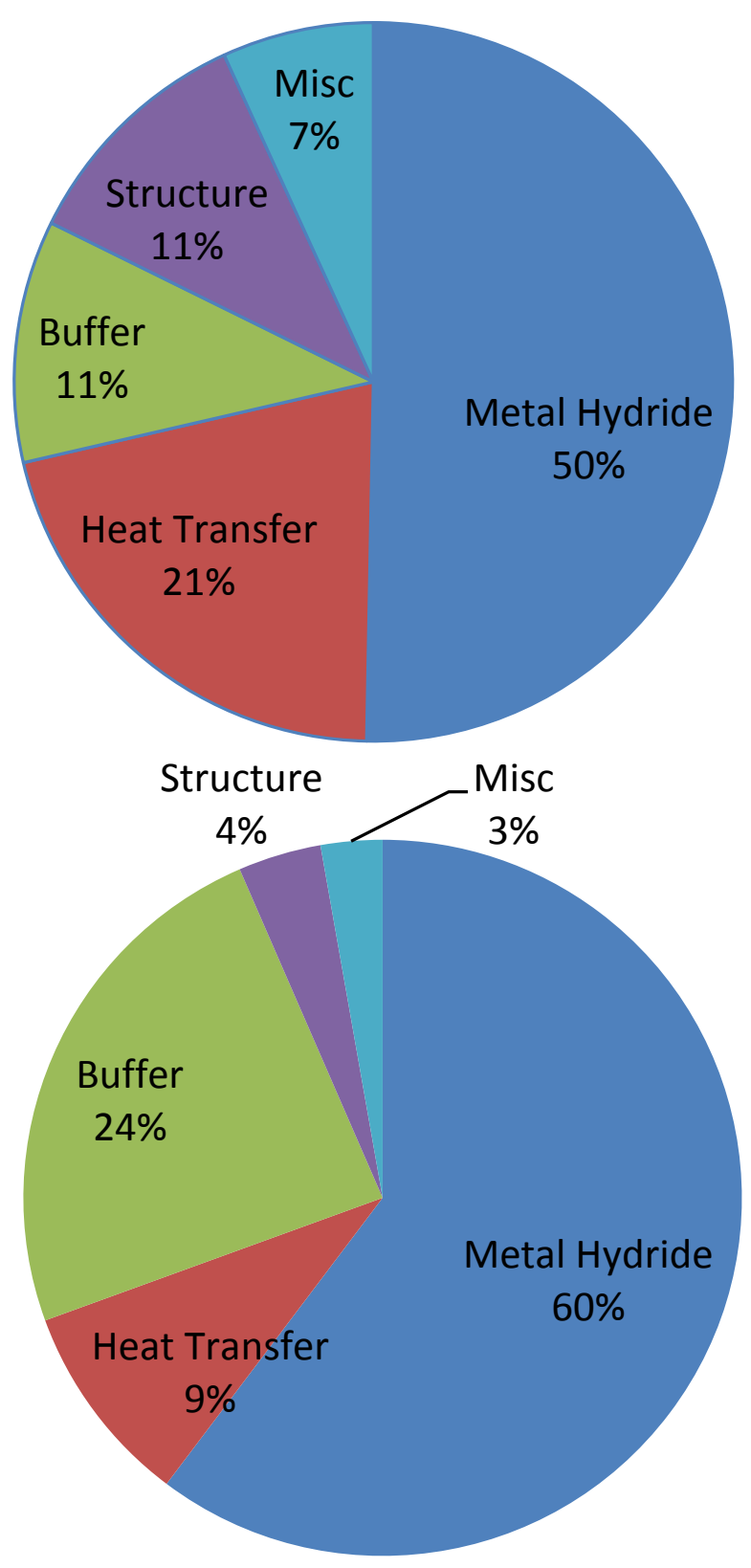

(a) Weight distribution (b) Volume distribution

Figure 11: Weight and volume distribution for a $\mathrm{H}_{2}$ storage system using a metal hydride with material properties that combine to satisfy all the system-level requirements listed in Table 1. 


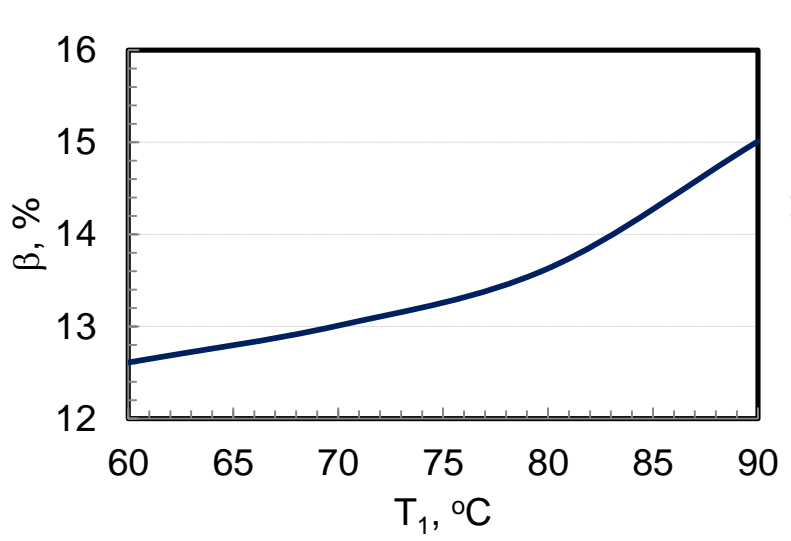

(a) Off-board coolant temperature

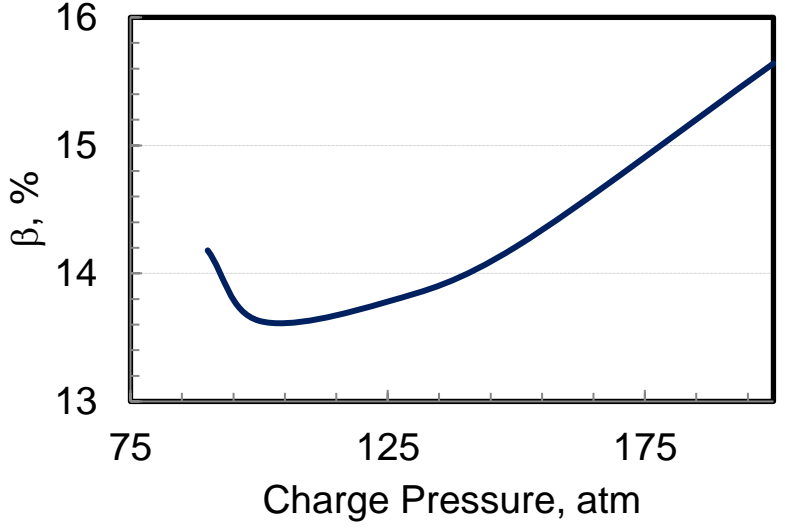

(b) Refueling pressure

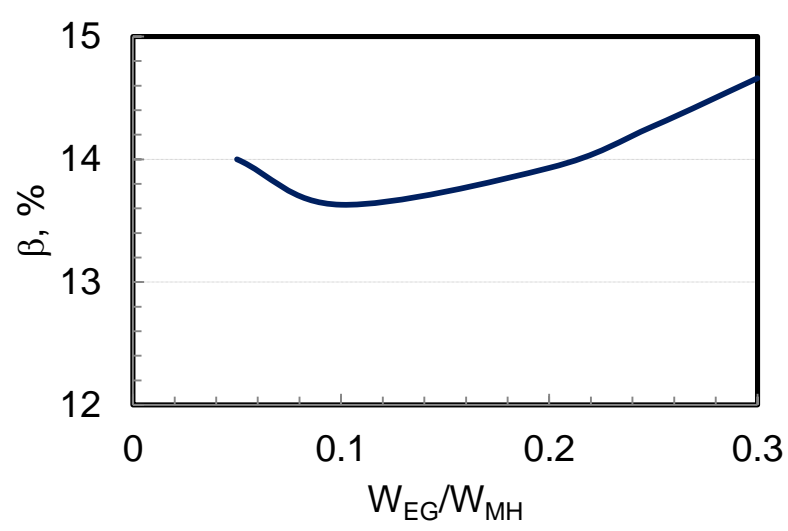

(c) $\mathrm{EG}$ to $\mathrm{MH}$ weight ratio

Figure 12: Single-parameter sensitivity study to examine the effect of off-board coolant temperature, refueling pressure and $\mathrm{EG}$ to $\mathrm{MH}$ weight ratio on intrinsic material capacity target 


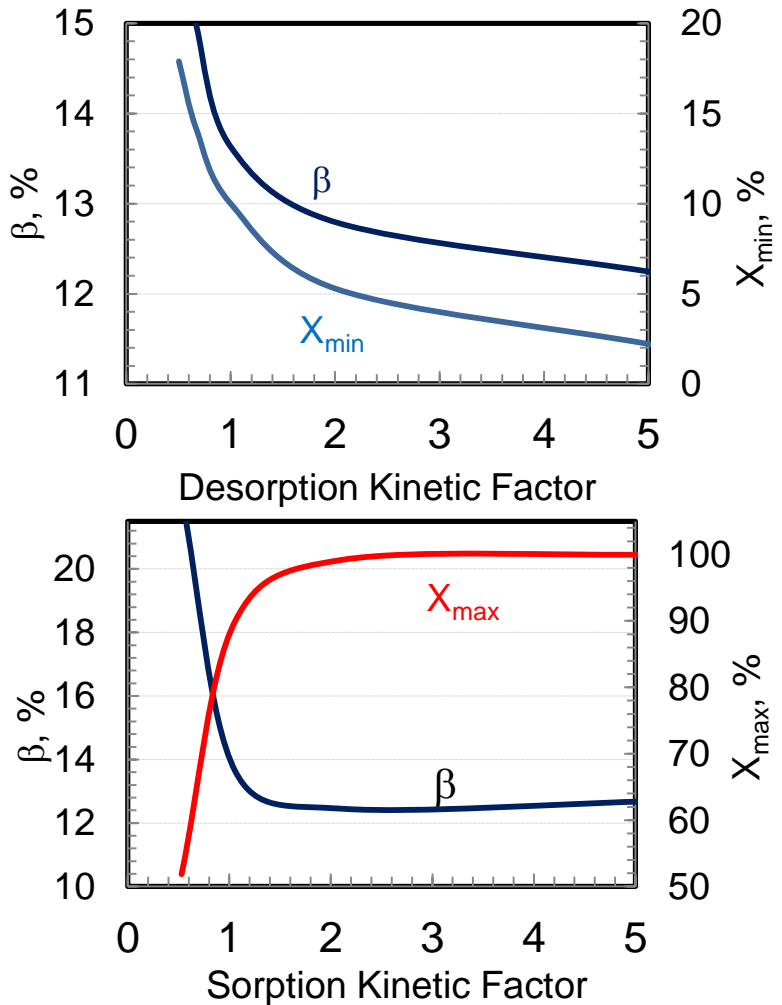

$\begin{array}{ll}\text { (a) Desorption kinetics } & \text { (b) Sorption kinetics }\end{array}$

Figure 13: Single-parameter sensitivity study to examine the effect sorption and desorption kinetics on intrinsic material capacity target 
Table 1: Technical System Targets for On-board Hydrogen Storage for Light-Duty Fuel Cell Vehicles

\section{Storage Parameter}

System Gravimetric Capacity:

Usable, specific-energy from $\mathrm{H}_{2}$ (net useful energy/max system mass)

\section{System Volumetric Capacity:}

Usable energy density from $\mathrm{H}_{2}$ (net useful energy/max system volume)

\section{Durability/Operability:}

Operating ambient temperature

Min/max delivery temperature

Operational cycle life (1/4 tank to full)

Min delivery pressure from storage system

Max delivery pressure from storage system

On-board efficiency

\section{Charging/Discharging Rates:}

System fill time $(5 \mathrm{~kg})$

Minimum full flow rate

Start time to full flow $\left(20^{\circ} \mathrm{C}\right)$

Start time to full flow $\left(-20^{\circ} \mathrm{C}\right)$

Transient response at operating temperature $10 \%-90 \%$ and $90 \%-0 \%$

$\begin{array}{ccc}\text { Units } & \mathbf{2 0 1 7} & \text { Ultimate } \\ \mathrm{kWh} / \mathrm{kg} & 1.8 & 2.5 \\ (\mathrm{~kg} \mathrm{H} / \mathrm{kg} \mathrm{system}) & (0.055) & (0.075) \\ \mathrm{kWh} / \mathrm{L} & 1.3 & 2.3 \\ (\mathrm{~kg} \mathrm{H} / \mathrm{L} \mathrm{system}) & (0.040) & (0.070) \\ & & \\ { }^{\circ} \mathrm{C} & -40 / 60 \text { (sun) } & -40 / 60 \text { (sun) } \\ { }^{\circ} \mathrm{C} & -40 / 85 & -40 / 85 \\ \mathrm{Cycles} & 1500 & 1500 \\ \mathrm{~atm} \mathrm{(abs)} & 5 & 3 \\ \text { atm (abs) } & 12 & 12 \\ \% & & 90 \\ \% & 90 & 2.5 \\ \mathrm{~min} & 3.3 & (2.0) \\ (\mathrm{kg} \mathrm{H} / \mathrm{min}) & (1.5) & 0.02 \\ (\mathrm{~g} / \mathrm{s}) / \mathrm{kW} & 0.02 & 5 \\ \mathrm{~s} & 5 & 15 \\ \mathrm{~s} & 15 & 0.75 \\ \mathrm{~s} & 0.75 & \end{array}$


Table 2: Properties of T700S Carbon Fiber and Composite (60\% fiber volume)

$\begin{array}{lccc}\text { Property } & \text { Unit } & \text { Fiber } & \text { Composite } \\ \text { Tensile Strength } & \mathrm{MPa} & 4900 & 2550 \\ \text { Tensile Modulus } & \mathrm{GPa} & 230 & 135 \\ \text { Tensile Strain } & \% & 2.1 & 1.7 \\ \text { Density } & \mathrm{kg} / \mathrm{m}^{3} & 1800 & 1580 \\ \text { Compressive Strength } & \mathrm{MPa} & & 1470 \\ \text { Flexural Strength } & \mathrm{MPa} & & 1670 \\ \text { Flexural Modulus } & \mathrm{GPa} & & 120\end{array}$


Table 3: Reverse Engineering Study Parameters

\begin{tabular}{|c|c|c|c|c|}
\hline Parameter & Units & $\begin{array}{c}\text { Reference } \\
\text { Values }\end{array}$ & $\begin{array}{c}\text { Range of } \\
\text { Values }\end{array}$ & Comments \\
\hline FCS Coolant Temperature & ${ }^{\circ} \mathrm{C}$ & $62-85$ & & Reference FCS [12] \\
\hline Off-Board Coolant Temperature & ${ }^{\circ} \mathrm{C}$ & 80 & $60-100$ & \\
\hline \multirow[t]{2}{*}{ MH Thermodynamics } & $\Delta \mathrm{S}, \mathrm{J} / \mathrm{mol} . \mathrm{K}$ & 110 & TBD & $\Delta \mathrm{H}_{\min }=26.8 \mathrm{~kJ} / \mathrm{mol}$ \\
\hline & $\Delta^{\mathrm{H}, \mathrm{kJ} / \mathrm{mol}}$ & 28 & TBD & $\Delta \mathrm{H}_{\max }=32.2 \mathrm{~kJ} / \mathrm{mol}$ \\
\hline Sorption Activation Energy & $\mathrm{E}_{\mathrm{c}}, \mathrm{kJ} / \mathrm{mol}$ & 45 & TBD & $\mathrm{NaAlH}_{4}$ data \\
\hline Minimum Delivery Pressure & atm & 5 & & DOE target [1] \\
\hline Minimum Full Flow Rate of $\mathrm{H}_{2}$ & $\mathrm{~g} / \mathrm{s}$ & 1.6 & & DOE target [1] \\
\hline Refueling Pressure & atm & 100 & $50-200$ & \\
\hline EG/MH Weight Ratio & & 0.1 & $0.05-0.25$ & IJHE (2003) 515-527 [22] \\
\hline System Gravimetric Capacity & \%wt. & 5.5 & & DOE target [1] \\
\hline System Volumetric Capacity & $g / L$ & 40 & & DOE target [1] \\
\hline
\end{tabular}


Table 4: Reference Metal Hydride Targets

\section{Variables}

$\mathrm{MH}$ Intrinsic Capacity

Fill Ratio

Sorption Kinetics

HX Tube Spacing

Mass of $\mathrm{MH}$

Buffer Tank Capacity
Related Variables

Bulk Density

Thermal Conductivity

$X_{\min }=10 \%$

$X_{\max }=90 \%$

Number of HX Tubes

Mass of Expanded

Natural Graphite

Weight of Al tank
Reference Values

$13.6 \%$ H capacity

$24.7 \%$ bed porosity

$589 \mathrm{~kg} / \mathrm{m}^{3} \mathrm{MH}$ bulk density

$8.4 \mathrm{~W} / \mathrm{m} . \mathrm{K}$ bed conductivity

$\tau_{\mathrm{d}}=16.8 \mathrm{~min}$

$\mathrm{k}_{\mathrm{C}}=4.2 \mathrm{~g} / \mathrm{kg}_{\mathrm{MH}} / \mathrm{min} / \mathrm{atm}$

$r_{2} / r_{1}=3.1$

$85 \mathrm{U}$ tubes

$51.2 \mathrm{~kg} \mathrm{MH}$

$5.1 \mathrm{~kg} \mathrm{EG}$

$11.1 \mathrm{~kg}$ buffer tank weight

33.7 L buffer tank volume

\section{Constraints}

$5.5 \mathrm{wt} \%$ gravimetric

$40 \mathrm{~g} / \mathrm{L}$ volumetric

$1.6 \mathrm{~g} / \mathrm{s} \mathrm{min} \mathrm{full} \mathrm{flow}$

$X_{\min }$ to $X_{\max }$ in $1.85 \mathrm{~min}$

$1.5 \mathrm{~kg} / \mathrm{min}$ refueling

$5.6 \mathrm{~kg}$ usable $\mathrm{H}_{2}$

Startup from $-40^{\circ} \mathrm{C}$ 